\title{
Acid or erythromycin stress significantly improves transformation efficiency through regulating expression of DNA binding proteins in Lactococcus lactis F44
}

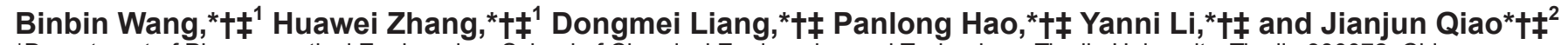 \\ *Department of Pharmaceutical Engineering, School of Chemical Engineering and Technology, Tianjin University, Tianjin 300072, China \\ †Key Laboratory of Systems Bioengineering, Ministry of Education Tianjin, 300072, China \\ ¥SynBio Research Platform, Collaborative Innovation Center of Chemical Science and Engineering, Tianjin 300072, China
}

\begin{abstract}
Lactococcus lactis is a gram-positive bacterium used extensively in the dairy industry and food fermentation, and its biological characteristics are usually improved through genetic manipulation. However, poor transformation efficiency was the main restriction factor for the construction of engineered strains. In this study, the transformation efficiency of L. lactis F44 showed a 56.1-fold increase in acid condition ( $\mathrm{pH} 5.0)$; meanwhile, erythromycin stress $(0.04 \mu \mathrm{g} / \mathrm{mL})$ promoted the transformation efficiency more significantly (76.9-fold). Notably, the transformation efficiency of F44e (L. lactis F44 harboring empty pLEB124) increased up to 149.1fold under the synergistic stresses of acid and erythromycin. In addition, the gene expression of some DNA binding proteins (DprA, RadA, RadC, RecA, RecQ, and SsbA) changed correspondingly. Especially for radA, 25.1-fold improvement was detected when F44e was exposed to $\mathrm{pH}$ 5.0. Overexpression of some DNA binding proteins could improve the transformation efficiency. The results suggested that acid or erythromycin stress could improve the transformation efficiency of $L$. lactis through regulating gene expression of DNA binding proteins. We have proposed a simple but promising strategy for improving the transformation efficiency of L. lactis and other hard-transformed microorganisms.

Key words: Lactococcus lactis, transformation efficiency, acid/erythromycin stress, DNA binding protein
\end{abstract}

Received July 1, 2017.

Accepted July 22, 2017.

${ }^{1}$ These authors contributed equally to this work.

${ }^{2}$ Corresponding author: jianjunq@tju.edu.cn

\section{INTRODUCTION}

Lactococcus lactis has been widely used in food fermentation, such as cheese, yogurt, pickle, and so on (Song et al., 2017). Moreover, it plays an important role in food preservation due to the secretion of lactic acid and nisin. Nisin, a bacteriocin consisting of $34 \mathrm{AA}$, was approved by the Joint Food and Agriculture Organization/World Health Organization as a safe food additive in 1969 and had been licensed in many countries. Recently, nisin had also been proved to have potential for the treatment of tissue infection and cancer (Shin et al., 2016). To improve nisin yield, genetic manipulation has been applied in the construction of engineered strains and proved to be an effective method (Zhang et al., 2016; Ni et al., 2017). However, it is difficult for exogenous DNA to be delivered into L. lactis. Improvement of transformation efficiency (TE) is urgently needed for genetic manipulation of L. lactis.

Electrotransformation has been widely used for genetic transformation in bacterium since its invention in the 1980s (Neumann et al., 1982; Xie and Tsong, 1993). Bacterial TE could be affected by several parameters, such as competent cell concentration, plasmid size, electroporation time, field strength, and so on ( $\mathrm{Lu}$ et al., 2014; Papagianni and Papamichael, 2014). Wu et al. (2009) improved TE by adjusting the field strength. Papagianni et al. (2007) achieved the goal by manipulating cell density.

Interestingly, dozens of bacteria could absorb and recombine exogenous DNA into their own genome spontaneously (Fontaine et al., 2015). The recombination process works with the assistance of several DNA binding proteins (DBP), such as DprA, RadA, and RecQ (Claverys and Martin, 2003). Lots of single-strand DNA binding proteins could maintain the stability of genome, and some of them are tightly associated with stress tolerance (Calhoun and Kwon, 2011; Zhu et al., 2015; Riber et al., 2016). On the other hand, TE was improved when the cells were exposed to adverse fac- 
tors, and the expression of stress-associated genes could be upregulated correspondingly (Holo and Nes, 1989; Slager et al., 2014).

To enhance the efficiency of genetic manipulation, we tried to improve TE of L. lactis F44. The significant improvement of TE was observed under acid or erythromycin stress, or both. To explore the mechanism, we detected the expression levels of 6 representative DBP genes $(d p r A, \operatorname{rad} A, \operatorname{rad} C, \operatorname{rec} A, \operatorname{rec} Q$, and $s s b A)$ by quantitative real-time (qRT) PCR; the transcriptional levels of genes of interest were improved discriminately under acid or erythromycin stress, or both. Overexpression assays indicated that TE was closely related to the upregulation of the DBP. This work shed light on the improvement of TE for the hardly transformed strains and provided a promising strategy for a wider application of L. lactis.

\section{MATERIALS AND METHODS}

\section{Bacterial Strains, Plasmids, and Media}

Escherichia coli TG1 was grown at $37^{\circ} \mathrm{C}$ with shaking at $220 \mathrm{rpm}$ in Luria-Bertani broth, which was used for cloning of plasmids pLEB124 and pNZ8048. Lactococcus lactis F44 was used as the original strain for the following experiments (Zhang et al., 2014). Lactococcus lactis F44e was constructed harboring the empty vector pLEB124, which contains constitutive p45 promoter and erythromycin resistance. All of the L. lactis strains were grown in seed medium (wt/vol; peptone $1.5 \%$, yeast extract $1.5 \%$, sucrose $1.5 \%, \mathrm{KH}_{2} \mathrm{PO}_{4} 2.0 \%$, $\mathrm{NaCl} 0.15 \%$, and $\mathrm{MgSO}_{4} \cdot 7 \mathrm{H}_{2} \mathrm{O} 0.015 \%$ ) at $30^{\circ} \mathrm{C}$ without agitation. The $\mathrm{pH}$ value was adjusted to 7.2 by $10 \mathrm{M} \mathrm{NaOH}$ before autoclaving at $115^{\circ} \mathrm{C}$ for $30 \mathrm{~min}$. Erythromycin $(5 \mu \mathrm{g} / \mathrm{mL})$ was added to the medium for F44e. Chloramphenicol $(5 \mu \mathrm{g} / \mathrm{mL})$ was added in seed medium after the electrotransformation of empty vector pNZ8048.

\section{Cell Growth Assay}

Lactococcus lactis F44 and F44e were incubated for 3 generations and cultured in seed medium with a different $\mathrm{pH}$ value $(7.0,6.0$, and 5.0). Optical density was measured at $600 \mathrm{~nm}$ every $2 \mathrm{~h}$ with a TU-1810 spectrophotometer (Persee, Beijing, China) to monitor cell growth. Similarly, growth of L. lactis F44 was also measured in the seed medium with different erythromycin concentrations $(0,0.01,0.02,0.03$, and $0.04 \mu \mathrm{g} / \mathrm{mL})$. In addition, the growth of L. lactis F44 and F44e were observed on acid solid medium. Bacterial cultures were diluted to $10^{-7}$ by $0.9 \% \mathrm{NaCl}$ solution and then spread $100 \mu \mathrm{L}$ on seed medium plates with different $\mathrm{pH}$ values
(7.0, 6.0, and 5.0; without antibiotic). Colony-forming units were measured every $12 \mathrm{~h}$.

\section{Electrotransformation}

Lactococcus lactis F44 and F44e were used as the targets for the electrotransformation. The strains were cultivated in the seed medium for 3 generations, then diluted 100-fold in secondary medium (seed medium supplemented with $1.5 \%$ sucrose and $1.5 \%$ glycine). The $\mathrm{pH}$ of secondary medium was adjusted to 7.0, 6.0, or 5.0 by $10 \% \mathrm{HCl}$ (wt/vol) or $10 M \mathrm{NaOH}$ before being used. Ampicillin was added to the medium at the final concentration of $20 \mu \mathrm{g} / \mathrm{mL}$ when the strains were cultured at $30^{\circ} \mathrm{C}$ for $6 \mathrm{~h}$. After incubation at $30^{\circ} \mathrm{C}$ for 1 $\mathrm{h}$, cells were harvested by centrifugation at 5,000 rpm for $5 \mathrm{~min}$ at $4^{\circ} \mathrm{C}$. The cells were centrifuged and washed 3 times, then resuspended with ice-cold washing buffer (containing $6.846 \%$ sucrose, $10 \%$ glycerine). Finally, the cell density was adjusted to $10^{9} \mathrm{cfu} / \mathrm{mL}$.

For electrotransformation, $1 \mu \mathrm{g}$ (about $6 \mu \mathrm{L}$ ) of pNZ8048 was added and gently mixed with $50 \mu \mathrm{L}$ of competent cells. The mixture was transferred into an ice-cold electroporation cuvette (2 $\mathrm{mm}$ gap). After a single electrical pulse at $2.4 \mathrm{kV} / \mathrm{cm}$, the cuvette was washed immediately with $1 \mathrm{~mL}$ of seed medium and incubated at $30^{\circ} \mathrm{C}$ for $3 \mathrm{~h}$, then spread on the seed medium supplemented with chloramphenicol at the final concentration of $5 \mu \mathrm{g} / \mathrm{mL}$. The number of mutants was counted after incubation at $30^{\circ} \mathrm{C}$ for $2 \mathrm{~d}$ ( Wu et al., 2009; Zhou et al., 2015; Joan et al., 2016). All of the experiments were conducted in triplicate and the average value was recorded, similarly hereinafter.

\section{RNA Isolation and Transcriptional Analysis by $q R T-P C R$}

Lactococcus lactis F44 and F44e were cultivated overnight in the seed medium and treated at different $\mathrm{pH}$ $(7.0,6.0,5.0$, and 4.0) respectively for $1 \mathrm{~h}$. Otherwise, L. lactis F44 was cultivated in the medium with different erythromycin concentrations $(0,0.01,0.02,0.03$, and $0.04 \mu \mathrm{g} / \mathrm{mL}$ ) for $1 \mathrm{~h}$. Fifty-milliliter cultures $\Delta \mathrm{ZR}$ RNAMiniPrep kit (ZYMO Research, Orange County, $\mathrm{CA}$ ) according to the manufacturer's instructions. The synthesis of cDNA was carried out with the TIANScript RT Kit (Fermentas, New York, NY) according to the manufacturer's protocol. The qRT-PCR were carried out in white 96-well LightCycler 480 Multiwell Plates on the LightCycler@ 480 (Roche Diagnostics, Penzberg, Germany) with Power SYBR Green PCR Master Mix (Applied Biosystems) according to the manufacturer's instructions. The primers are listed in Supplemental Table S1 (https://doi.org/10.3168/jds.2017-13101). 
Reactions were run in triplicate on 3 independent experiments for each condition. The qRT-PCR conditions were as follows: 1 cycle at $95^{\circ} \mathrm{C}$ for $10 \mathrm{~min}, 40$ cycles of denaturation at $95^{\circ} \mathrm{C}$ for $10 \mathrm{~s}$, annealing at $55^{\circ} \mathrm{C}$ for $10 \mathrm{~s}$, and extension at $72^{\circ} \mathrm{C}$ for $20 \mathrm{~s}$. The $16 \mathrm{~S}$ rRNA gene was used as an internal control to normalize cycle threshold $\left(\mathbf{C}_{\mathbf{T}}\right)$ values. The relative quantification of expression was calculated using the $2^{-\Delta \Delta \mathrm{CT}}$ method after the threshold cycle (Cheon et al., 2012; Li et al., 2015; Zhang et al., 2016).

\section{Construction of Overexpression Strains}

Genomic DNA of L. lactis F44 (mid-exponential phase of growth) was extracted with TIANamp Bacterial DNA kit (Tiangen Biotech, Beijing, China) following the manufacturer's protocol. However, a preliminary cell disruption was carried out with $200 \mathrm{mg} /$ $\mathrm{mL}$ of lysozyme solution. The genes of interest were amplified from genomic DNA of L. lactis F44 with the corresponding primers as listed in Supplemental Table S2 (https://doi.org/10.3168/jds.2017-13101). The PCR products and pLEB124 were digested by BamHI and $S m a I$ and were recovered from agarose gels. All DNA fragments were ligated into the shuttle vector pLEB124 and then transferred into the competent E. coli TG1. Subsequently, E. coli TG1 were plated onto LuriaBertani broth agar with $50 \mu \mathrm{g} / \mathrm{mL}$ of erythromycin and analyzed with colony PCR. After the extraction from E. coli TG1, all the plasmids were introduced into competent L. lactis $\mathrm{F} 44$ by electrotransformation using the MicroPulser Electroporator (Bio-Rad, Hercules, CA). In addition, the competence of engineering strains was prepared at $\mathrm{pH} 5.0$ and then applied to the TE assay.

\section{RESULTS}

\section{Growth Characteristics of L. lactis F44 and F44e Under Different Acid or Erythromycin Stress, or Both}

We tested the growth character of L. lactis F44 and F44e at different $\mathrm{pH}(7.0,6.0$, and 5.0). The biomass decreased along with the declining of initial $\mathrm{pH}$ value of medium (Figure 1A), and the final $\mathrm{pH}$ values were approximating to 4.6 (Supplemental Figure S1; https:// doi.org/10.3168/jds.2017-13101). Apparently, acid stress had significant inhibitory effects on the growth of these strains. Likewise, erythromycin could also inhibit the growth of L. lactis. Therefore, we investigated the growth of L. lactis F44 under different erythromycin concentrations from 0 to $5 \mu \mathrm{g} / \mathrm{mL}$ and concluded that the sublethal concentrations of erythromycin ranged from 0.01 to $0.05 \mu \mathrm{g} / \mathrm{mL}$. As shown in Figure 1B, the
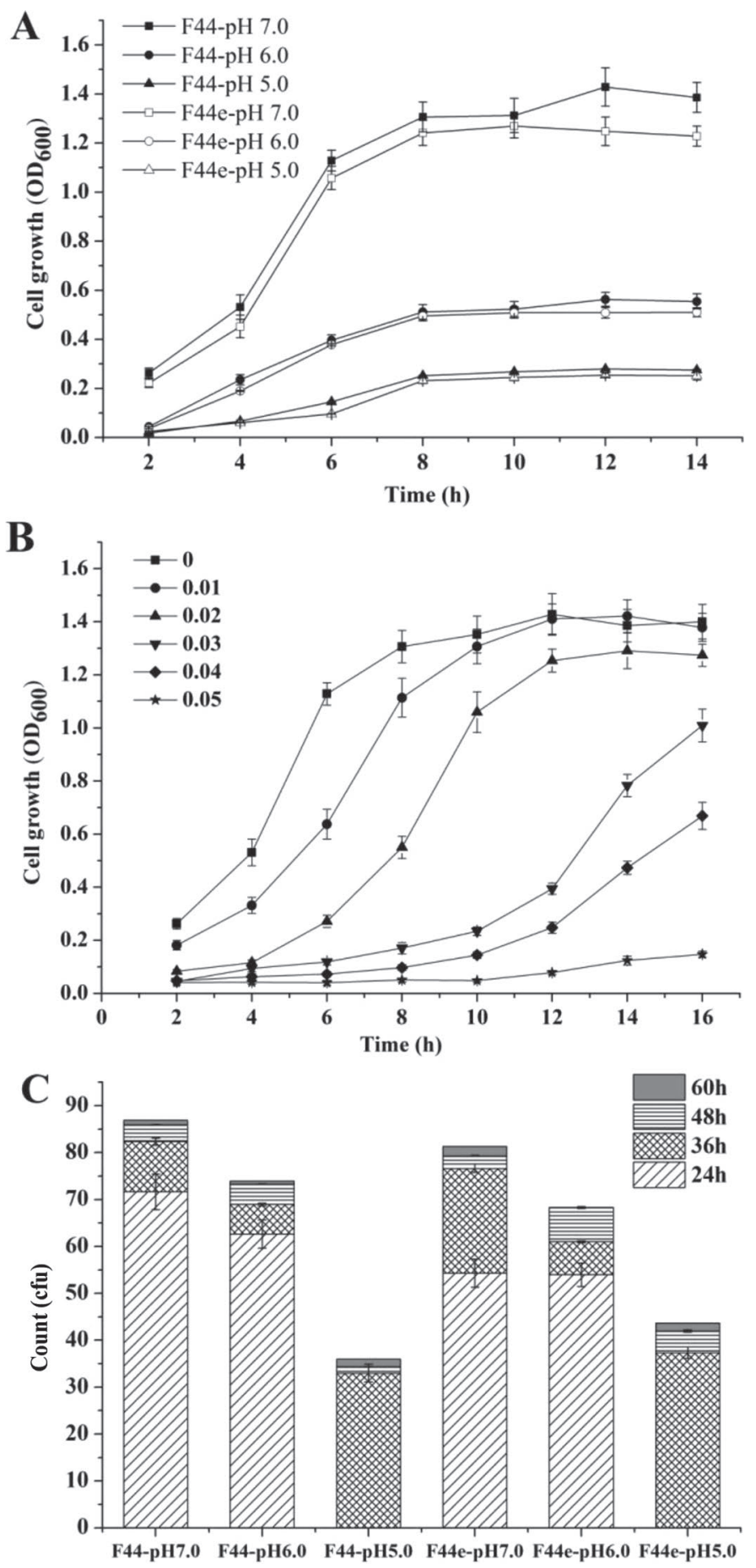

Figure 1. Growth characteristics of Lactococcus lactis F44 and F44e under different conditions. (A) Growth curves of L. lactis F44 and F44e; cells were inoculated into different $\mathrm{pH}$ seed medium (harboring $5 \mu \mathrm{g} / \mathrm{mL}$ of erythromycin for F44e) and measured at optical density at $600 \mathrm{~nm}\left(\mathrm{OD}_{600}\right)$. (B) Growth curves of L. lactis F44 in seed medium (harboring $0,0.01,0.02,0.03,0.04$, and $0.05 \mu \mathrm{g} / \mathrm{mL}$ of erythromycin) and measured at $\mathrm{OD}_{600}$. (C) Lactococcus lactis $\mathrm{F} 44$ and $\mathrm{F} 44 \mathrm{e}$ were spread on seed medium plates with different $\mathrm{pH}$ and the colonyforming units were measured every $12 \mathrm{~h}$. Error bars are SD from 3 independent experiments. 
final biomass and growth rate of L. lactis F44 decreased with the increase of erythromycin concentration.

To further explore the influence of acid stress or erythromycin on L. lactis, the colony-forming units were detected by using L. lactis F44 and F44e (Figure 1C). The results showed that acid stress could inhibit the growth of L. lactis. An obvious colony on medium plates with $\mathrm{pH} 5.0$ could only be found after $36 \mathrm{~h}$ of cultivation, and the colony size was smaller (data not shown). Few colonies of F44e were observed in $\mathrm{pH} 6.0$ and 7.0 than that of F44. Interestingly, more colonies of L. lactis $\mathrm{F} 44 \mathrm{e}$ were observed in acid conditions ( $\mathrm{pH} 5.0$ ) compared with L. lactis F44 (Figure 1C). Therefore, we speculated that the increased survival rate of $L$. lactis $\mathrm{F} 44 \mathrm{e}$ comparing with F44 under acid stress might result from the activation of some intrinsic factor by erythromycin.

\section{TE of L. lactis Influenced by Acid or Erythromycin}

Previous studies showed that several bacterial TE were improved under the stress of antibiotics or concentrated $\mathrm{NaCl}$ (Palomino et al., 2010; Shanker and Federle, 2017). Therefore, it was speculated that acid or erythromycin, or both, could improve the TE of L. lactis F44. As shown in Figure 2A and Supplemental Figure S2 (https://doi.org/10.3168/jds.2017-13101), the TE of L. lactis $\mathrm{F} 44$ and $\mathrm{F} 44 \mathrm{e}$ at $\mathrm{pH} 5.0$ could increase up to 56.1- and 149.1-fold compared with that at $\mathrm{pH} 7.0$, respectively. Moreover, the TE of L. lactis F44e with $5 \mu \mathrm{g} /$ $\mathrm{mL}$ of erythromycin at $\mathrm{pH} 5.0$ was 350 -fold higher than that of L. lactis F44 without erythromycin stimulation at $\mathrm{pH}$ 7.0. The results indicated that TE of L. lactis F44 could be improved under acid and erythromycin stresses. Furthermore, we examined the erythromycin effect on TE of L. lactis F44. As shown in Figure 2B and Supplemental Figure S3 (https://doi.org/10.3168/ jds.2017-13101), more positive colonies were obtained under acute erythromycin stress. Especially, the TE of L. lactis F44 (with $0.04 \mu \mathrm{g} / \mathrm{mL}$ of erythromycin) could be increased up to 76.9-fold compared with the control (no erythromycin added). These results further verified that erythromycin could improve TE of L. lactis F44 without the influence of pLEB124.

\section{Transcriptional Levels of DBP Genes Under Acid or Erythromycin Stress}

To assess the transcriptional levels of DBP under acid or erythromycin stress, or both, the transcripts of $d p r A, \operatorname{rad} A, \operatorname{rad} C, \operatorname{rec} A, \operatorname{rec} Q, s s b A$ in $L$. lactis $\mathrm{F} 44$ and F44e were monitored by qRT-PCR. The results showed that the expression level of these DBP genes increased along with the $\mathrm{pH}$ value decreasing in L. lactis $\mathrm{F} 44$
(Figure 3A and Supplemental Table S3, https://doi .org/10.3168/jds.2017-13101). Likewise, the same trend was observed in L. lactis F44e, and the expression levels of these genes increased more obviously, especially for $d p r A, \operatorname{radA}$, and $s s b A$ (Figure $3 \mathrm{~B}$ and Supplemental Table S4, https://doi.org/10.3168/jds.2017-13101), suggesting that erythromycin stress could also induce the expression increase of the DBP genes. As shown in Figure 3C and Supplemental Table S5 (https://doi.org/ 10.3168/jds.2017-13101), the expression levels of these genes increased with the intensification of erythromycin stress. These results verified that the response to environmental stress might be a trigger to the expression of DBP, resulting in the increased TE of L. lactis.
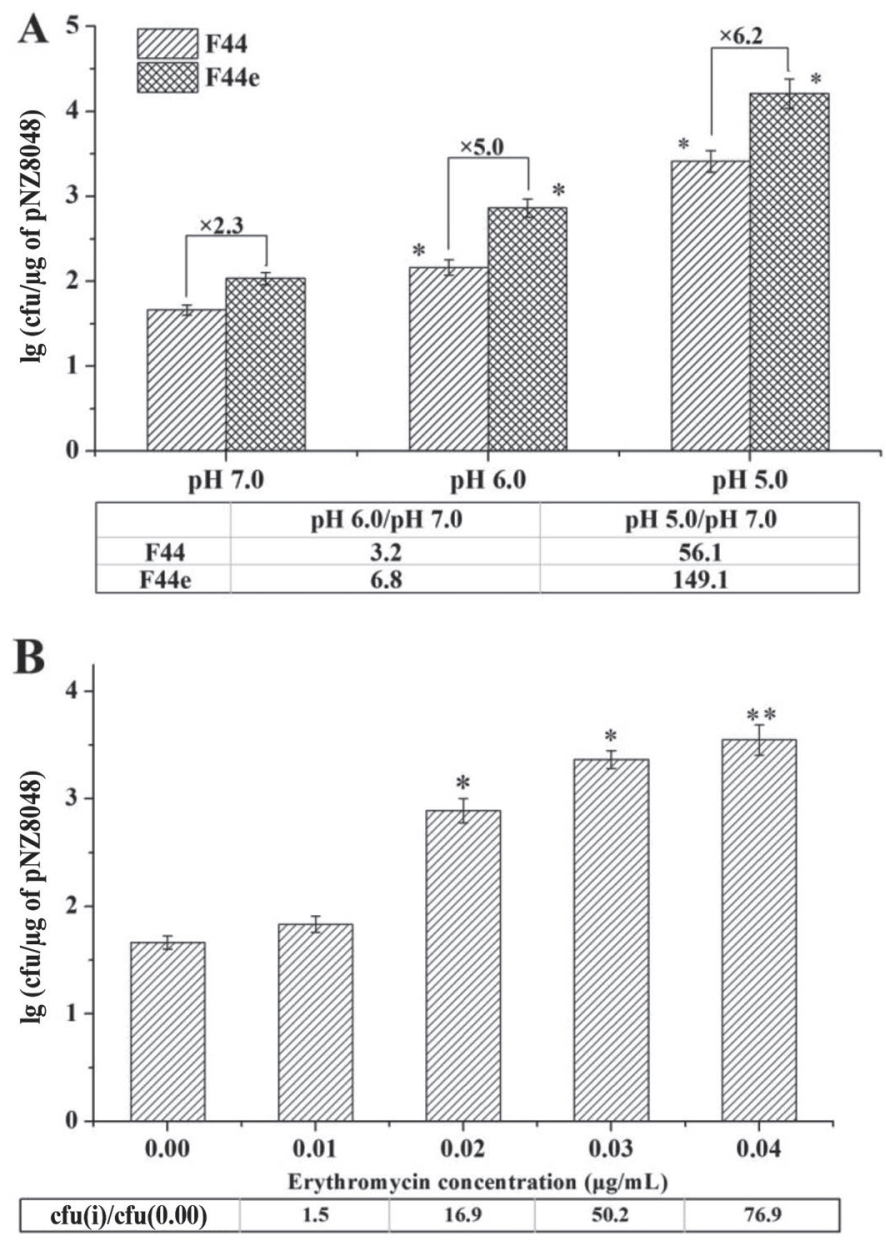

Figure 2. Transformation efficiency (TE) of Lactococcus lactis influenced by acid and erythromycin. The TE was indicated by colonyforming units per microgram of pNZ8048. (A) The TE of L. lactis F44 and F44e under acid stress; competence cells were prepared after culturing in secondary mediums with different $\mathrm{pH}$. (B) The TE of $L$. lactis F44 influenced by erythromycin. Competence cells were prepared at different erythromycin concentrations $(0,0.01,0.02,0.03$, and $0.04 \mu \mathrm{g} / \mathrm{mL}$ ). Error bars are SD from 3 independent experiments. ${ }^{*} P$ $<0.05,{ }^{* *} P<0.01 ; t$-test. 

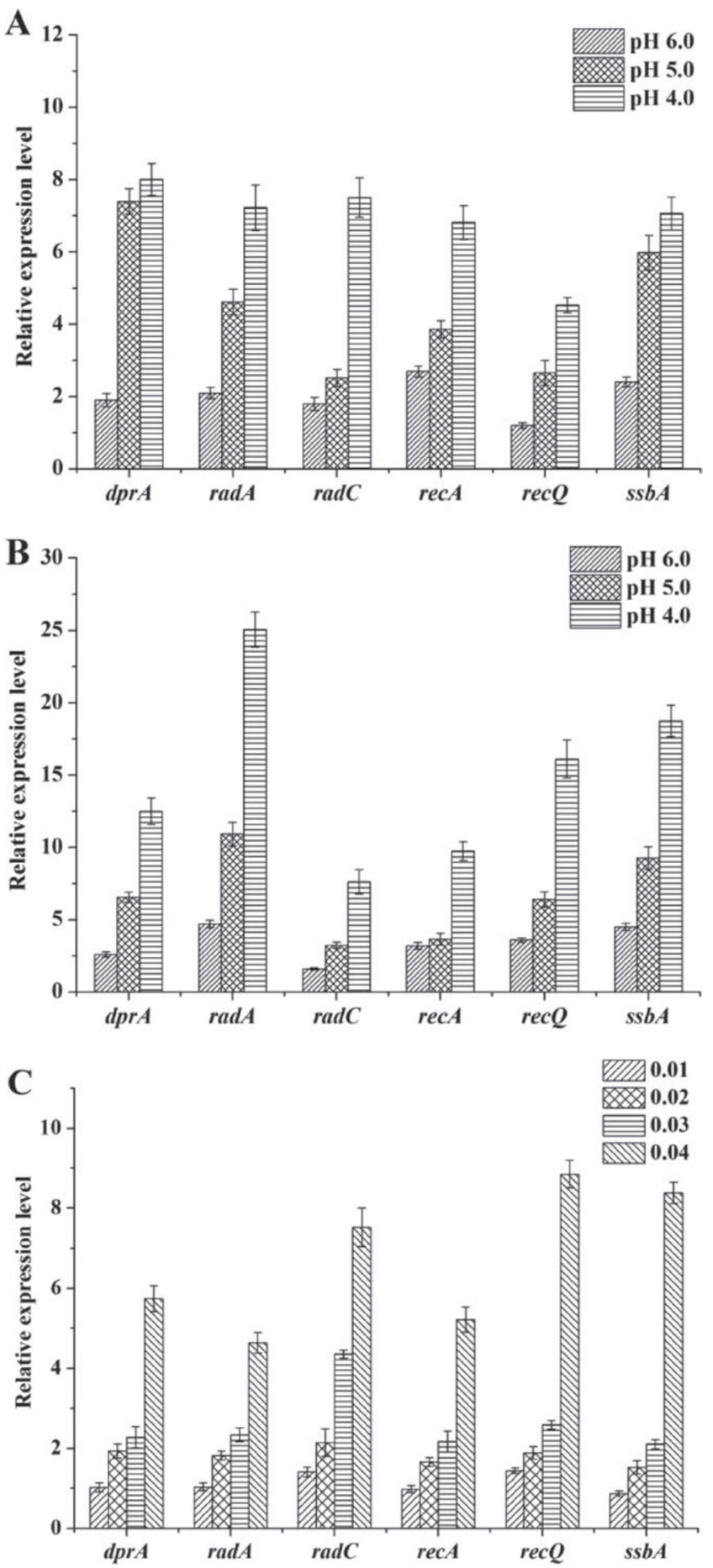

Figure 3. Transcript levels of 6 DNA binding proteins (DBP) genes with quantitative real-time PCR measurements. The internal control gene was $16 \mathrm{~S}$ rRNA. Fold change of genetic transcription was calculated based on threshold cycle. (A) Relative expression levels in F44 at different $\mathrm{pH}$; the external control ( $\mathrm{pH}$ 7.0) was set as 1-fold (invisible) for each gene. (B) The relative expression levels in F44e at different $\mathrm{pH}$ values; the external control ( $\mathrm{pH}$ 7.0) was set as 1-fold (invisible) for the corresponding gene. (C) The relative expression levels after being provoked at different concentrations of erythromycin $(0.01,0.02,0.03$, and $0.04 \mu \mathrm{g} / \mathrm{mL}$ ); the external control (no erythromycin) was set as 1 -fold (invisible). Error bars are SD from 3 independent experiments.

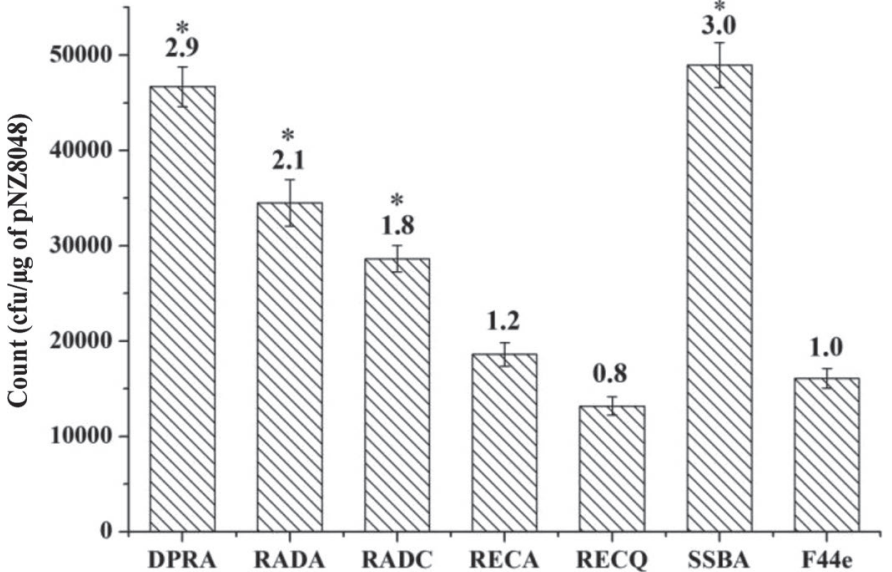

Figure 4. Transformation efficiency (TE) of strains overexpressing DNA binding protein (DBP) gene. Competence cells were prepared at $\mathrm{pH}$ 5.0. The DPRA, RADA, RADC, RECA, RECQ, and SSBA represent the strain overexpressing $d p r A, \operatorname{rad} A, \operatorname{rad} C, \operatorname{rec} A, \operatorname{rec} Q$, and $s s b A$, respectively. The number on the column represented the change fold of TE, colony-forming units (objective)/colony-forming units (F44e). Error bars are SD from 3 independent experiments. ${ }^{*} P<0.05$; $t$-test.

\section{Effects of DBP Overexpression on TE of L. lactis F44}

To investigate the influence of DBP on TE, we overexpressed these genes in L. lactis F44 and measured the $\mathrm{TE}$ of the engineering strains, respectively. As shown in Figure 4, the increased expression levels of DBP genes, especially $\operatorname{dpr} A$ (2.9-fold) and $s s b A$ (3.0-fold), has a strong effect on TE of L. lactis F44.

\section{DISCUSSION}

In the present work, we reported for the first time that acid or erythromycin stress could significantly $(P<0.05)$ improve the TE of $L$. lactis. Moreover, the qRT-PCR results showed that the expression level of DBP genes was remarkably enhanced correspondingly. We also explored the effect of 6 DBP on TE through the overexpression assays.

Lactococcus lactis, a safe microorganism for humans and animals, has been widely used in the dairy industry (Rodrigues et al., 2016). Meanwhile, bio-engineered strains were usually used for the production of the industrially valuable compound (Zhang et al., 2014). However, the construction of engineered strains was hindered by low TE, similar to some gram-positive bacteria. In this study, we first found that TE of $L$. lactis was significantly $(P<0.05)$ improved under acid stress (Figure 2A and Supplemental Figure S2, https:// doi.org/10.3168/jds.2017-13101). In addition, the TE improvement of $L$. lactis $\mathrm{F} 44 \mathrm{e}$ was more significant $(P$ $<0.05$ ) than that of F44 (Figure 2A and Supplemental Figure S2, https://doi.org/10.3168/jds.2017-13101), 
which indicated that erythromycin stress could also promote TE of L lactis. To further verify this speculation, we tested TE of L. lactis F44 under erythromycin stress with various concentrations (Figure 2B and Supplemental Figure S3, https://doi.org/10.3168/jds.2017 -13101). The results showed that erythromycin could significantly $(P<0.01)$ improve TE of $L$. lactis also.

Some DBP are closely related to genomic stability; their expression levels would be improved when the cell was exposed to adverse factors (Burghout et al., 2007; Liang et al., 2013). Acid or erythromycin could result in the growth inhibition and TE improvement of L. lactis F44, which inspired us to investigate the related mechanism. The expression levels of several DBP genes were enhanced significantly under acid stress (Figure 3A). It was speculated that the instability of DNA under acid stress could trigger the higher expression of some DBP genes (Karas et al., 2015). Moreover, a similar result was obtained under erythromycin stress (Figure 3C). Thus, we inferred that the transformation efficiency was associated with the higher expression levels of DBP genes under acid or erythromycin stress.

The DprA and SsbA could bind with the exogenous single-strand DNA to maintain its stability (QuevillonCheruel et al., 2012). Moreover, DNA repair proteins RadA and RadC play important roles in response to DNA damaging agents, methyl methanesulfonate, hydroxyurea, and UV radiation (Burghout et al., 2007; Liang et al., 2013). In addition, RecA is responsible for searching the corresponding homologous region on genome, and RecQ (helicase) could repetitively unwind and reanneal double-stranded DNA regions during the homologous recombination (Harami et al., 2017; Kochugaeva et al., 2017). Six representative DBP were overexpressed for further verification, and the results demonstrated that DBP played important roles in TE.

On the basis of our results, the TE of L. lactis F44 could be improved under acid or erythromycin stress. Moreover, we confirmed that the interaction between TE and DBP was involved in acid/erythromycin stress response, which might shed light on the potential application of L. lactis in the food and dairy industries.

\section{CONCLUSIONS}

In this study, we first reported that the TE of L. lactis F44 could be improved significantly $(P<0.05)$ by acid or erythromycin stress, or both. Further analysis showed that higher TE of F44 under acid or erythromycin stress, or both, was mediated with the increased expression of DBP. Lactococcus lactis may be engineered more easily and used more widely in dairy industry based on our discoveries. Remarkably, this work also provided a novel method for genetic manipulation of hardly transformed bacteria.

\section{ACKNOWLEDGMENTS}

This program was financially supported by the National Key Technology Support Program (2015BAD16B04), the National Natural Science Foundation of China $(31570049,32570089)$, and the Funds for Creative Research Groups of China (21621004). Jianjun Qiao was supported by The New Century Outstanding Talent Support Program, Education Ministry of China, Beijing.

\section{REFERENCES}

Burghout, P., H. J. Bootsma, T. G. Kloosterman, J. J. Bijlsma, C. E. de Jongh, O. P. Kuipers, and P. W. Hermans. 2007. Search for genes essential for Pneumococcal transformation: The RADA DNA repair protein plays a role in genomic recombination of donor DNA. J. Bacteriol. 189:6540-6550.

Calhoun, L. N., and Y. M. Kwon. 2011. Structure, function and regulation of the DNA-binding protein DPS and its role in acid and oxidative stress resistance in Escherichia coli: A review. J. Appl. Microbiol. 110:375-386.

Cheon, G. J., C. Yuan, D.-S. Yeon, S.-C. Kwon, and B.-G. Park. 2012. Mechanisms of motility change on trinitrobenzenesulfonic acid-induced colonic inflammation in mice. Korean J. Physiol. Pharmacol. 16:437-446.

Claverys, J. P., and B. Martin. 2003. Bacterial 'competence' genes: Signatures of active transformation, or only remnants? Trends Microbiol. 11:161-165.

Fontaine, L., A. Wahl, M. Fléchard, J. Mignolet, and P. Hols. 2015. Regulation of competence for natural transformation in Streptococci. Infect. Genet. Evol. 33:343-360.

Harami, G. M., Y. Seol, J. In, V. Ferencziová, M. Martina, M. Gyimesi, K. Sarlós, Z. J. Kovács, N. T. Nagy, Y. Sun, T. Vellai, K. C. Neuman, and M. Kovács. 2017. Shuttling along DNA and directed processing of D-loops by RecQ helicase support quality control of homologous recombination. Proc. Natl. Acad. Sci. USA 114:E466E475.

Holo, H., and I. F. Nes. 1989. High-frequency transformation, by electroporation, of Lactococcus lactis ssp. cremoris grown with glycine in osmotically stabilized media. Appl. Environ. Microbiol. 55:3119-3123.

Joan, S. S., J. Pui-Fong, A. A. Song, L. Y. Chang, K. Yusoff, S. AbuBakar, and R. A. Rahim. 2016. Oral vaccine of Lactococcus lactis harbouring pandemic H1N1 2009 haemagglutinin1 and nisP anchor fusion protein elevates anti-HA1 sIgA levels in mice. Biotechnol. Lett. 38:793-799.

Karas, V. O., I. Westerlaken, and A. S. Meyer. 2015. The DNA-binding protein (DPS) from starved cells utilizes dual functions to defend cells against multiple stresses. J. Bacteriol. 197:3206-3215.

Kochugaeva, M. P., A. A. Shvets, and A. B. Kolomeisky. 2017. On the mechanism of homology search by RecA protein filaments. Biophys. J. 112:859-867.

Li, J., Q. Ding, F. Wang, Y. Zhang, H. Li, and J. Gao. 2015. Integrative analysis of mRNA and miRNA expression profiles of the tuberous root development at seedling stages in turnips. PLoS One 10:e0137983.

Liang, P. J., W. Y. Han, Q. H. Huang, Y. Z. Li, J. F. Ni, Q. X. She, and Y. L. Shen. 2013. Knockouts of RecA-like proteins RadC1 and RadC2 have distinct responses to DNA damage agents in Sulfolobus islandicus. J. Genet. Genomics 40:533-542.

Lu, S., Y. Nie, Y. Q. Tang, G. Xiong, and X. L. Wu. 2014. A critical combination of operating parameters can significantly increase the 
electrotransformation efficiency of a Gram-positive Dietzia strain. J. Microbiol. Methods 103:144-151.

Neumann, E., M. Schaefer-Ridder, Y. Wang, and P. H. Hofschneider. 1982. Gene transfer into mouse lyoma cells by electroporation in high electric fields. EMBO J. 1:841-845.

Ni, Z. J., X. Y. Zhang, F. Liu, M. Wang, R. H. Hao, P. X. Ling, and X. Q. Zhu. 2017. Effect of co-overexpression of nisin key genes on nisin production improvement in Lactococcus lactis LS01. Probiotics Antimicrob. Proteins 9:204-212. https://doi.org/10.1007/ s12602-017-9268-8.

Palomino, M. M., M. C. Allievi, M. Prado-Acosta, C. Sanchez-Rivas, and S. M. Ruzal. 2010. New method for electroporation of Lactobacillus species grown in high salt. J. Microbiol. Methods 83:164-167.

Papagianni, M., N. Avramidis, and G. Filioussis. 2007. High efficiency electrotransformation of Lactococcus lactis spp. Lactis cells pretreated with lithium acetate and dithiothreitol. BMC Biotechnol. $7: 15$.

Papagianni, M., and E. M. Papamichael. 2014. Plasmid transformation of Weissella paramesenteroides DX by electroporation. Anaerobe 30:60-64.

Quevillon-Cheruel, S., N. Campo, N. Mirouze, I. Mortier-Barrière, M. A. Brooks, M. Boudes, D. Durand, A. L. Soulet, J. Lisboa P. Noirot, B. Martin, H. van Tilbeurgh, M. F. Noirot-Gros, J. P. Claverys, and P. Polard. 2012. Structure-function analysis of pneumococcal DprA protein reveals that dimerization is crucial for loading RecA recombinase onto DNA during transformation. Proc. Natl. Acad. Sci. USA 109:E2466-E2475.

Riber, L., J. Frimodt-Møller, G. Charbon, and A. Løbner-Olesen. 2016. Multiple DNA binding proteins contribute to timing of chromosome replication in E. coli. Front. Mol. Biosci. 3:29.

Rodrigues, M. X., S. F. Lima, C. H. Higgins, S. G. Canniatti-Brazaca, and R. C. Bicalho. 2016. The Lactococcus genus as a potential emerging mastitis pathogen group: A report on an outbreak investigation. J. Dairy Sci. 99:9864-9874.

Shanker, E., and M. J. Federle. 2017. Quorum sensing regulation of competence and bacteriocins in Streptococcus pneumoniae and mutans. Genes (Basel) 8:E15.
Shin, J. M., J. W. Gwak, P. Kamarajan, J. C. Fenno, A. H. Rickard, and Y. L. Kapila. 2016. Biomedical applications of nisin. J. Appl. Microbiol. 120:1449-1465.

Slager, J., M. Kjos, L. Attaiech, and J. W. Veening. 2014. Antibioticinduced replication stress triggers bacterial competence by increasing gene dosage near the origin. Cell 157:395-406.

Song, A. A., L. L. In, S. H. Lim, and R. A. Rahim. 2017. A review on Lactococcus lactis: From food to factory. Microb. Cell Fact. 16:55.

Wu, Z., Z. Xuanyuan, R. Li, D. Jiang, C. Li, H. Xu, Y. Bai, X. Zhang, H. Turakainen, P. E. J. Saris, H. Savilahti, and M. Qiao. 2009. $\mathrm{Mu}$ transposition complex mutagenesis in Lactococcus lactis-identification of genes affecting nisin production. J. Appl. Microbiol. 106:41-48

Xie, T. D., and T. Y. Tsong. 1993. Study of mechanisms of electric field-induced DNA transfection. V. Effects of DNA topology on surface binding, cell uptake, expression, and integration into host chromosomes of DNA in the mammalian cell. Biophys. J. 65:1684-1689.

Zhang, J., Q. Caiyin, W. Feng, X. Zhao, B. Qiao, G. Zhao, and J. Qiao. 2016. Enhance nisin yield via improving acid-tolerant capability of Lactococcus lactis F44. Sci. Rep. 6:27973.

Zhang, Y. F., S. Y. Liu, Y. H. Du, W. J. Feng, J. H. Liu, and J. J. Qiao. 2014. Genome shuffling of Lactococcus lactis subspecies lactis YF11 for improving nisin Z production and comparative analysis. J. Dairy Sci. 97:2528-2541.

Zhou, H., Y. Gao, G. Gao, and Y. Lou. 2015. Oral administration of recombinant Lactococcus lactis expressing the cellulase gene increases digestibility of fiber in geese. Curr. Microbiol. 71:693-698.

Zhu, L., J. Lin, Z. Kuang, J. E. Vidal, and G. W. Lau. 2015. Deletion analysis of Streptococcus pneumoniae late competence genes distinguishes virulence determinants that are dependent or independent of competence induction. Mol. Microbiol. 97:151-165. 